\title{
O DESENVOLVIMENTO DE COMPETÊNCIAS EMPREENDEDORAS NA ADMINISTRAÇÃO PÚBLICA: UM ESTUDO COM EMPREENDEDORES CORPORATIVOS NA PREFEITURA DE BLUMENAU, SANTA CATARINA
} DEVELOPING AN ENTREPRENEURIAL COMPETENCE IN PUBLIC ADMINISTRATION: A CASE STUDY WITH CORPORATE ENTREPRENEURSHIP IN THE CITY OF BLUMENAU, SANTA CATARINA

\section{Fernando Cesar Lenzi}

Doutor em Administração pela Faculdade de Economia e Administração da Universidade
Recebido em: 24/02/2012 Aceito em: 09/04/2012

Federal de São Paulo - USP.Professor do Programa de Mestrado em Administração da Universidade do Vale do Itajaí - UNIVALI

\section{Flavio Ramos}

Doutor em Sociologia Política pela Universidade Federal de Santa Catarina - UFSC. Professor do Programa de Mestrado em Gestão de Políticas Públicas da Universidade do Vale do Itajaí - UNIVALI

\section{Emerson Antonio Maccari}

Doutor em Administração pela Faculdade de Economia e Administração da Universidade de São Paulo - USP. Professor do Programa de Mestrado Profissional em Administração - Gestão de Projetos - pela Universidade Nove de Julho - UNINOVE

\section{Cristina Dai Pra Martens}

Doutora em Administração pela Universidade Federal do Rio Grande do Sul - UFRGS.Professora do Programa de Mestrado Profissional em Administração - Gestão de Projetos - pela Universidade Nove de Julho - UNINOVE.

\section{RESUMO}

Esta pesquisa teve como objetivo identificar as competências dos empreendedores corporativos ligados à administração pública. O estudo foi realizado por meio de uma abordagem investigativa com 25 servidores públicos envolvidos no desenvolvimento de projetos inovadores na Prefeitura de Blumenau, em Santa Catarina, cidade que é caracterizada pela excelência em projetos de inovação e pelo desenvolvimento de ações empreendedoras. A pesquisa ressalta que os resultados inovadores têm sua origem em comportamentos manifestos por estes indivíduos a partir do ambiente propício estimulado por um programa de empreendedorismo corporativo. O Programa de Inovação e Melhoria - PIM busca capacitar e desenvolver os servidores públicos para serem empreendedores em suas atividades. Os resultados apontam as seguintes competências empreendedoras que mais se destacam: (a) comprometimento; (b) busca de informações; (c) persistência; (d) planejamento e monitoramento sistemático; (e) persuasão; e (f) rede de contatos. Assim, pode-se afirmar que, ao se desenvolverem estas competências, os servidores públicos estarão mais preparados para empreender e inovar.

Palavras-chave: empreendedor corporativo; competências empreendedoras; administração pública.

\section{ABSTRACT}

This research aimed to identify the entrepreneurial competence of workers linked to public administration. It was conducted through a survey of 25 public workers involved in the development of innovative projects in the City of Blumenau-SC, a city that is recognized by excellence in innovation projects and development of entrepreneurial actions. The research highlights that the results have their origin in innovative behaviors manifest by these individuals from the environment stimulated by a program of corporate entrepreneurship. The Program for Innovation and Improvement - Pll, seeks to qualify and to develop the public workers to be entrepreneurs in their activities. The results indicate the following entrepreneurial competence that stand out: a) commitment b) seeking information, c) persistence; d) planning and systematic monitoring e) Persuasion; and f) networking. Thus, it can be stated that by developing these skills, public servants will be better prepared to undertake and innovate.

Keywords: corporate entrepreneur; entrepreneurial competence; public administration.

Emerson Antonio Maccari

maccari@uninove.br
Cristina Dai Pra Martens cristinadpmartens 


\section{INTRODUÇÃO}

No estudo da evolução do fenômeno do empreendedorismo como conhecimento acumulado e consequente formulação de teorias, podem-se identificar várias abordagens pelos autores nesta área. Uma dessas abordagens trata dos empreendedores internos nas organizações públicas e privadas, que se comportam de forma a lidar com os projetos corporativos desenvolvidos nas diversas áreas.

Pinchot (1989: 29) mencionou que "ser um intrapreneur é, de fato, um estado de espírito. Este estado não é necessariamente estabelecido na infância; ele pode ser desenvolvido em qualquer ponto da vida, dados o desejo e a oportunidade". Este contexto revela a possibilidade presente em todas as pessoas para este desenvolvimento, dependendo das condições do meio e dos objetivos pessoais de cada individuo. Porém, as afirmações de Pinchot (1989) e outros autores não revelaram estudos aprofundados que identifiquem e caracterizem o empreendedor corporativo de maneira consistente, mostrando o espaço que há para o desenvolvimento de projetos inovadores.

Os estudos sobre empreendedores corporativos vêm ganhando significativo espaço na pesquisa acadêmica. Porém, ainda são poucos os trabalhos nesta linha e, em menor número, os voltados à administração pública. Nesse sentido, a presente pesquisa objetiva identificar as competências dos empreendedores corporativos ligados à administração pública, na busca de resultados constantes de inovação, renovação estratégica e desenvolvimento de novos serviços comunitários.

O problema considerado nesta pesquisa esteve centrado na identificação do conjunto de competências empreendedoras dos profissionais que atuam em projetos inovadores na área pública, configurando uma base de evidências que possibilitam o crescimento do empreendedorismo corporativo na administração pública. A partir deste problema, centrou-se o foco do estudo na identificação do reconhecimento da presença de empreendedores corporativos na gestão pública, na análise das ações que levam à configuração de competências empreendedoras nos indivíduos pesquisados, bem como na comparação dos empreendedores corporativos da área pública com suas ações de inovação e desenvolvimento de novos projetos.

Com esta pesquisa, é possível investigar a existência e o reconhecimento de profissionais em- preendedores nas empresas públicas e suas respectivas competências, servindo de base para a prática de outras empresas públicas que ainda não adotaram estes conceitos e práticas.

O presente artigo está estruturado da seguinte forma: na sequência desta introdução, é feita uma retomada conceitual sobre os temas "empreendedorismo", "competências", "empreendedorismo corporativo" e "gestão pública"; após, é apresentada a metodologia utilizada na pesquisa; em seguida, são divulgados os resultados do estudo empírico desenvolvido; e, por fim, são feitas as considerações finais do trabalho.

\section{EMPREENDEDORISMO}

Considerando o enfoque de entrepreneurship, Araújo relatou que

[...] o empreendedor sem dúvida é alguém que assume riscos e inova, mas tendo em mente um objetivo empresarial preciso - o de iniciar e manter um negócio independente - sendo o entrepreneurship o processo de criação e desenvolvimento de negócios autônomos, baseados na inovação sistemática (ARAúJo, 1988: 67).

Nestes aspectos, o referido autor defendeu que gestão de empresas e empreendedores estão diretamente relacionados sem poder separá-los.

Paralelamente a essas concepções, o mesmo autor relatou que o intrapreneurship também pode ser considerado como um processo de criação e desenvolvimento de negócios, mas não independentes, e sim vinculados às médias e grandes empresas. Considerase que há diferença entre o processo tradicional de expansão/diversificação e o controle de intrapreneurship. O primeiro ocorre de forma mecânica e não participativa, enquanto o segundo também estimula alternativas de expansão e diversificação através de uma dinâmica coletiva que envolve os diversos escalões da empresa, e de uma ampla visão estratégica com uma cultura empreendedora efetivamente impregnada no dia a dia da organização. É esta fusão entre visão e espírito empreendedor que vai promover um clima organizacional propício à criatividade e à inovação. Ainda segundo Araújo (1988: 70), "a mola propulsora deste processo é o intraempreendedor e seu estilo de trabalho em rede com outros intraempreendedores disseminados pelas várias áreas e níveis da empresa". 
O desafio das organizações está em buscar a cooperação dos funcionários para todas as atividades relacionadas aos ideais do empreendedor, tornando seus subordinados intraempreendedores. Cox defendeu que

[...] o desafio mais importante a levar em conta consiste em convencer subordinados que você realmente lhes acolhe com prazer, ideias e iniciativas, fazendo-os de uma maneira que tornará mais úteis os esforços que despenderem. E o modo mais interessante de fazer isso é servir-lhes de modelo como pensador e realizador (Cox, 1994: 118).

Seguindo este raciocínio, identificou-se a necessidade de o empreendedor estar envolvido profissionalmente com todos à sua volta dentro da empresa. Para isso, o próprio Cox sugeriu uma ação proativa do gestor:

[...] como chefe, promova o desempenho do seu departamento mostrando aos subordinados que, para você, as iniciativas têm que ser eficazes em termos práticos, e bem pensadas. E mostre-lhes que suas próprias ideias - por mais sólidas e inventivas que sejam - têm que passar pelo crivo final da ação. Observando-lhe o exemplo, esses ambiciosos subordinados aprendem que você lhes apreciará uma orientação igual (Cox, 1994: 119).

Apesar da linguagem voltada para uma empresa com grande estrutura hierárquica, podemos fazer a mesma analogia para os empreendedores que se dispõem a atuar em mercados mais competitivos. Se este empreendedor quiser ter suas ações plenamente realizadas com o auxílio e o envolvimento de outras pessoas, ele deverá estar constantemente fazendoas agir pelo exemplo e pelo modelo de iniciativa.

A necessidade de profissionais mais hábeis nas organizações traz à tona alguns aspectos revelados como comportamentos empreendedores em funcionários de maior destaque, retratando o empreendedorismo corporativo, que se caracteriza, essencialmente, pelo desenvolvimento de projetos inovadores nas organizações. Nesse contexto, a oportunidade e o desejo individual são elementos importantes (PINCHOT, 1989). No entanto, Degen (1989: 10) apontou que "[...] há muitos fatores que inibem o surgimento de novos empreendedores. Os três mais importantes são: imagem social, disposição de assumir riscos e capital social dos potenciais empreendedores". Estes fatores mencionados formam um conjunto de barreiras que são comumente identificadas em pessoas que, mesmo com um potencial intraempreendedor forte, não conseguem partir para uma atividade própria isolada ou em sociedade.

Leite (1998: 30) fez uma alusão aos jovens executivos, dizendo que "[...] somente as pessoas que ousam desafiar as dificuldades de uma economia chegarão ao seu destino com sucesso". Essas dificuldades surgem tanto num empreendimento próprio como em empreendimentos onde há intraempreendedores envolvidos. Certamente, o sucesso estará presente com aqueles que ousarem e se comportarem adequadamente. Porém, para sair de uma situação de intraempreendedor para empreender em negócio próprio, há algumas distinções. Leite (1998: 76) apontou que "aqueles que tentam arriscar-se por conta própria sem adequado preparo físico, psicológico e financeiro sofrerão bastante, pois, acostumados a terem toda infraestrutura organizacional à sua disposição, terão de enfrentar o enorme desafio da sobrevivência de seu negócio num mercado aberto e altamente competitivo".

\section{COMPETÊNCIAS}

O conceito de competência vem ganhando destaque com inigualável rapidez, pois é considerado como o elo entre conhecimento e estratégia. Alguns autores falam também em capital intelectual, um ativo intangível, que têm como base conhecimentos, habilidades, valores, atitudes das pessoas que participam do núcleo decisório de uma organização'. A competência individual, por um lado, seria a experiência, o

\footnotetext{
${ }^{1} \mathrm{O}$ conceito de competência individual pode ser compreendido a partir da evolução do conceito de qualificação, bastante utilizado em décadas anteriores. A qualificação sempre foi utilizada em relação ao cargo ou à função, centrado na formação técnica ou educacional da pessoa, do ocupante do cargo. O modelo de competência é mais abrangente, pois envolve uma perspectiva mais ampla do ambiente organizacional e das estratégias empresariais. As exigências atualmente estão além das qualificações profissionais, fazendo parte de um campo subjetivo de análise. Para aprofundar o assunto, ver obras organizadas por Dutra (2001) e Valle (2003). É imprescindível ler a obra recente de Scenett (2006), onde o referido autor ressaltou o conceito de "sociedade das capacitações" e que o trabalhador deve perseguir, permanentemente, novas habilidades e novas posturas para sobreviver no mundo das organizações.
} 
background, a educação, bem como conhecimentos, habilidades, valores e atitudes das pessoas que desenvolvem atividades profissionais nas organizações do conhecimento. As competências organizacionais, por outro lado, seriam constituídas pelo conjunto de conhecimentos, habilidades, tecnologias e comportamentos que uma organização possui. Os conceitos são próximos e, muitas vezes, confundem o leitor. 0 importante é que as competências essenciais nas empresas possam apresentar o diferencial competitivo exigido. Essas competências serão consideradas "essenciais" quando reconhecidas pelos clientes, e não adaptadas pelos concorrentes.

O tema "competência" tem sido amplamente discutido por autores como McClealland (1972), Pinchot (1989, 2004), Pinchot \& Pellman (2004), Drucker (1986), Cooley (1990, 1991), Farrel (1993), Spencer Jr. \& Spencer (1993), Miner (1998), Fleury (2002) e Dutra (2004), os quais desenvolveram uma abordagem voltada ao ambiente organizacional atual. Nesse contexto, torna-se essencial entender o conceito de forma específica para que se possa definir o foco desta pesquisa.

Orsi \& Bose (2003) mencionaram que a primeira abordagem sobre competência surgiu com Spencer Jr. \& Spencer (1993) e McClelland (1972), que a definiram como um conjunto de qualificações que a pessoa tem para executar um trabalho com um nível superior de desempenho. Os estudos iniciados por McClelland (1972) sustentavam uma base em que o estoque de conhecimentos, habilidades e atitudes é que definem o nível de competência de um indivíduo.

A evolução do estudo de Spencer Jr. \& Spencer, realizada por Cooley (1990, 1991), evidencia que a competência se manifesta através de ações nas quais há a entrega, e não apenas um estoque de conhecimentos, habilidades e atitudes. Fleury (2002) reforçou este ponto de vista ao afirmar que diversos autores da escola europeia - com destaque para Lawler (1996) e Le Boterf (1994) - descreveram a entrega como fundamento básico para o desenvolvimento de competências individuais.

Dutra (2001) foi mais longe, ao apresentar o conceito de "entrega" ao exemplificar a forma como cada trabalhador deve contribuir para o sucesso organizacional e com as organizações, utilizando-se de uma "fita métrica" para mensurar desempenhos.
Ora, a intenção de mensurar é, evidentemente, controlar. Esta parece ser a lógica dessa modalidade. Mas, na atualidade, não se está a criticar justamente as chamadas organizações burocráticas², tayloristas, que privilegiavam formas de controle? Não se está a buscar o oposto? Equipes autogerenciáveis, responsabilidades compartilhadas não seriam o desenho ideal de uma organização do século XXI? Uma vez mais, o discurso em torno das teorias e práticas de recursos humanos apresenta-se de forma ambígua.

Uma pergunta ainda persiste: e para onde vão as propostas humanistas do aprendizado organizacional como formas de construir organizações que permitam o livre diálogo, a construção coletiva baseada em redes interativas de pessoas, em processos cognitivos etc.?

Lipovetsky (2005: 249) ressaltou que, a partir do discurso envolvendo o modelo participativo e de construção coletiva, "[...] os ideais vêm à frente, mas na realidade o que entra em questão é a eficácia da empresa". Talvez seja essa a explicação para o paradoxo enfatizado por Mascarenhas, Vasconcelos \& Vasconcelos (2004: 76) ao registrarem que os indivíduos encontram dificuldades operacionais para implementar, a partir novos discursos sobre gestão de pessoas, "[...] novas estruturas e comportamentos, o que intensifica a percepção polarizada nas dimensões discurso e prática no sistema organizacional".

Dutra (2001: 42) assinalou, por exemplo, que "[...] as habilidades deram lugar à caracterização das entregas requeridas dos indivíduos e as atitudes deram lugar aos comportamentos observáveis". Não se está, portanto, a tratar de novas formas de controle?

Bauman (2007: 161) registrou o drama dessa "entrega" pessoal, pois "[...] submeter os esforços humanos de autoafirmação e autoaperfeiçoamento a visões essencialmente imprevisíveis e sabidamente não confiáveis das futuras necessidades dos voláteis e caóticos mercados acarreta muito sofrimento para as pessoas".

Na prática, essa entrega deve se manifestar no papel profissional de cada indivíduo, indo ao encontro da proposta da empresa onde se trabalha. Muitas vezes, ainda

\footnotetext{
2 Entendem-se organizações burocráticas no sentido weberiano, ou seja, organizações racionalmente estruturadas, com níveis hierárquicos e descrições de funções bem definidas.
} 
que a pessoa possua todo o conhecimento necessário para sua colocação no mercado, falta-lhe realizar uma união mais evidente deste conhecimento com atitudes que estejam interligadas às suas habilidades para, então, poder entregar-se à organização por meio de ações que demonstrem sua competência.

Chauí (2004) alertou, no entanto, para o caráter ideológico do conceito de competência, pois os que possuem determinado conhecimento estariam mais aptos do que os outros para o exercício do poder. Ou seja, todos estariam a lidar com uma concepção de exclusão e de diferenciação, pois haveria os competentes e os incompetentes. E quais seriam os critérios para efetivamente serem definidas competências?

Para Fleury (2002), a noção de competência está associada a expressões do tipo: saber agir, mobilizar recursos, integrar saberes múltiplos e complexos, saber aprender, saber se engajar, assumir responsabilidades e ter visão estratégica, gerando resultados e ações realizadas (entrega). Portanto, do ponto de vista da empresa, as competências devem agregar valor econômico, e, do ponto de vista individual, elas devem acrescentar valor social às pessoas. Nessa linha de raciocínio, Fleury (2002) ainda evidenciou que as competências de cada colaborador contribuem para a formação ou sustentação das competências essenciais à organização, permitindo a esta atender aos clientes no mercado em que atua. Le Boterf (1994) apresentou uma estrutura de competências reforçada por Fleury (2002). Os três componentes fundamentais dessa estrutura são os seguintes: o saber agir, o querer agir e o poder agir.

\section{EMPREENDEDORISMO CORPORATIVO}

A base de estudos do empreendedorismo corporativo, considerando-se as corporações empreendedoras e os empreendedores corporativos (intraempreendedores) citados por Pinchot III (1989), Pinchot \& Pellman (2004), Seiffert \& Santos (2004) e Seiffert (2005), reside, principalmente, nos aspectos relacionados à inovação e ao aproveitamento de novas oportunidades.

\section{Drucker (1986: 25) ponderou a respeito:}

A inovação é o instrumento específico dos empreendedores, o meio pelo qual eles exploram a mudança como uma oportunidade para um negócio diferente ou um serviço diferente. Ela pode bem ser apresentada como uma disciplina, ser aprendida e ser praticada. Os empreendedores precisam buscar, com propósito deliberado, as fontes de inovação, as mudanças e seus sintomas que indicam oportunidades para que uma inovação tenha êxito. E os empreendedores precisam conhecer e pôr em prática os princípios da inovação bem-sucedida.

A preocupação das organizações em, constantemente, buscar novos mercados, novos produtos, novas alternativas de negócios e maior eficácia em suas operações levam a este quadro de inovação que caracteriza um ambiente propício ao desenvolvimento de ações empreendedoras.

Do ponto de vista da empresa e de seus empreendedores ou acionistas, a inovação é o caminho para o crescimento de mercado. Pinchot \& Pellman (2004: 29) consideraram que "a inovação é necessária como fator diferencial na oferta, como meio de localizar e preencher nichos ainda não ocupados no mercado e como forma de manter-se atualizado em relação à produtividade da concorrência".

O gerenciamento da inovação é uma das tarefas mais desafiadoras nas empresas que partem para este território de ação. Isto ocorre, pois a forma de atuação das corporações em geral é balizada pela busca de resultados conforme planejado. Por outro lado, a inovação exige uma forma de atuação diferenciada, onde o futuro é desconhecido, mas deve ser revelado. E é justamente nesta linha que Pinchot \& Pellman (2004) comentaram o tema, dizendo que o sucesso nas ações inovadoras é originado da rápida aprendizagem e da pronta resposta ao novo aprendizado.

O maior desafio para as organizações nestes cenários de inovação e mudança não é, apenas, conseguir planos que contemplem estas incertezas. Mas, principalmente, identificar pessoas na organização que saibam lidar com estes ambientes formados a partir dos contextos mal definidos com muita antecedência.

Quanto à criação de novas organizações, o efeito mais comum do empreendedorismo corporativo é a criação de novos negócios ou projetos inovadores para uma determinada organização. Isto não significa que deva, apenas, ser criada nova organização. O fato de se criarem projetos inovadores com equipes 
formadas por projetos pode ser considerado como um fenômeno característico do objeto citado. Também a criação de unidades estratégicas de negócios pode ser considerada como resultado de uma ação empreendedora na corporação. Esta visão foi corroborada por Zahra (1991) quando mencionou que o empreendedorismo corporativo está relacionado à criação de novos negócios em empresas já criadas ou renovação estratégica de um negócio já existente.

Já o fato de apenas se instigar a renovação ou inovação não pode ser caracterizado como fator de definição do empreendedorismo corporativo. Além de instigar mudanças, devem ser aplicadas as propostas de modo a se obterem os resultados adequados ao desenvolvimento da empresa no mercado. Essa visão foi fortalecida por Seiffert \& Santos (2004), comentando que o empreendedorismo corporativo aglutina as ações de criação, renovação ou inovação que ocorrem dentro ou fora da organização; e por Lenzi (2008) e Lenzi et al. (2011) quando argumentaram que as competências empreendedoras são originadas por resultados constantes dos empreendedores corporativos, e não apenas de ações pontuais, que auxiliam, também, na observação do empreendedorismo corporativo na gestão pública.

\section{GESTÃO PÚBLICA}

Os estudos envolvendo políticas públicas no Brasil são relativamente recentes. A década de 1980 inaugurou uma sequência de trabalhos contemplando o tema, fruto do processo de democratização do País. Cidadania, direitos humanos, saúde, educação e as ações sociais do Estado brasileiro constituíram esse ambiente fecundo para que as políticas públicas e seus enfoques sociais ganhassem destaque. Houve um esforço acentuado para que tais ações fossem devidamente analisadas, incluindo aspectos que envolvem a formulação dessas políticas como sua efetividade. As relações entre Estado e sociedade, adquirindo novos patamares, privilegiam atores até então não contemplados por estudos do gênero.

No Brasil, a Constituinte de 1988, apesar do debate em torno do (neo)liberalismo no início da década de 1990, definiu, em grande parte, o desenho do Estado brasileiro e as concepções de políticas públicas a partir dessa nova arquitetura do referido Estado.
A redemocratização criou um ambiente mais propício para que os cidadãos pudessem participar de um debate mais amplo, envolvendo os assuntos que afetam a sociedade e o espaço público. Destacase a consolidação da esfera municipal como responsável pelo desenvolvimento local (CRFB, artigo 182 e ss). Os espaços públicos não estatais tornam-se arenas de negociação entre as diversas instituições públicas e as demandas da sociedade (VIEIRA, 2001; Frey, 2004; Gugliano, 2004; Nogueira, 2004, 2008; Paes DE PAULA, 2005). Em todo o caso, fenômenos da cultura política (como patrimonialismo e clientelismo) e de origem do período autoritário (como as medidas provisórias como instrumento de legislação direta do Executivo) (v. CodATo, 2005) ainda permanecem na formação do Estado e dos governos. Este cenário ainda foi acionado por vertentes de oposições ideológicas como marcas de debates e posicionamentos políticos e de luta pelo poder.

A década de 1990, no Brasil, contemplou instigante debate envolvendo o desenho do Estado e as reformas administrativas englobando a estrutura burocrática brasileira. A ideologia (neo)liberal conhecia seu apogeu. Não foi por acaso que as reformas administrativas que contemplaram organizações públicas e a busca por flexibilidade nos modelos de gestão foram associadas a esse movimento de escala global. $\mathrm{O}$ discurso liberal afirmava que o Estado era perdulário e ineficaz. A esquerda reagia e acusava os reformadores de seguirem os ditames do neoliberalismo, mas estava em consonância com a necessidade de mudança do Estado; o caminho a seguir é que marcava a distinção.

Esse debate, em parte, foi superado. A abordagem neoliberal cedeu espaço para novas formas de crescimento econômico, Welfare State e democracia. Draibe (2007) assinalou que possivelmente todos estejam a vivenciar, não apenas no Brasil, uma nova fase de política desenvolvimentista em que o Estado assume compromissos abandonados desde meados da década de 1980. Independentemente das divergências envolvendo o tema, fatos como a intervenção do Estado assumindo a promoção de políticas de desenvolvimento ganharam destaque na atualidade.

Por outro lado, mas conectada com essas preocupações, está a própria dinâmica e efetividade da construção de modelos de gestão voltados às especificidades das organizações públicas. Como foi ressaltado anteriormente e de forma independente do 
debate com forte carga ideológica, alguns aspectos ligados às reformas administrativas não podem ser desconsideradas. Resende (2002, 2009) dedicou significativo interesse para desvendar os obstáculos e desafios que envolvem as tentativas, nem sempre bem-sucedidas, das reformas administrativas. A resistência às modificações e os interesses diversos dos principais atores políticos envolvidos nos processos de mudança impedem o avanço das mesmas. O estorvo parece se estabelecer na dificuldade entre a reforma do Estado e a manutenção do poder.

No caso específico das reformas administrativas, haverá sempre a preocupação sobre a efetividade das políticas públicas e os resultados esperados, e nem sempre atingidos, pelos formuladores dessas mesmas políticas. O comportamento, a atitude e os interesses dos agentes são determinantes para o sucesso ou fracasso dessas iniciativas. É difícil, no entanto, generalizar "modelos de gestão" para as organizações públicas. Independentemente do fato de o "modelo" ser "tecnocrático", "participativo", "gerencial", "societal", "popular", "burocrático" etc., as especificidades organizacionais e as ações dos agentes irão determinar o comportamento organizacional. A cultura e as especificidades organizacionais são desprezadas pela maior parte das análises envolvendo "modelos de gestão" para as organizações públicas. Organizações não são modificadas por modelos impostos a partir dos governantes, sejam estes liberais, sejam conservadores, socialdemocratas ou socialistas. A relação entre pessoas (agentes) e estruturas (instituições), apesar dos modelos apresentados, fazem uma organização. Ain$\mathrm{da}$, as relações entre estes agentes e as estruturas propiciam redenhos permanentes e vagarosos de mudanças. Em quaisquer circunstâncias, as estruturas e os agentes passam a interferir mutuamente e sobre si mesmas, numa circunstância de se manterem fechados (como forma de conservar suas condições atuais) e abertos (como forma de negociação permanente com outras instâncias). Estas próprias relações podem ser consideradas como outro ente na composição deste cenário.

O debate envolvendo empreendedorismo nas organizações públicas torna-se, portanto, essencial para que novas propostas de gestão proporcionem o enriquecimento das alternativas dos novos desenhos do Estado contemporâneo e de suas práticas gestionárias.

\section{METODOLOGIA}

Gil (1999) destacou a possibilidade de utilização de vários métodos para realização de pesquisa, a saber, o dedutivo, indutivo, hipotético-dedutivo, dialético, fenomenológico. Neste estudo foi utilizado o método "indutivo", por meio do qual se investiga um caso em particular para chegar a possíveis generalidades. Mattar (1996) considerou que esse método se caracteriza pela coleta de opiniões dos elementos da amostra. Seus resultados podem apontar a predominância de certas opiniões da população, que levam à elaboração de diretrizes para a construção da teoria.

Conforme indicaram Mattar (1996), Cooper \& Schindler (1995), esta pesquisa pode ser classificada como "ocasional" por apresentar um único levantamento de informações, embora seja possível repetila posteriormente, de maneira ampliada, estabelecendo-se um horizonte temporal das atitudes empreendedoras dos servidores públicos.

A natureza da pesquisa busca gerar conhecimento para uma aplicação prática do resultado, ou seja, a identificação do ambiente favorável ao empreendedorismo corporativo das organizações públicas. Os dados utilizados são considerados "primários" com as informações coletadas diretamente da população, especialmente para esta pesquisa (MATTAR, 1996).

O universo da pesquisa é caracterizado por 70 participantes de um programa de formação empreendedora na Prefeitura Municipal de Blumenau, considerados neste estudo como empreendedores corporativos, que foram selecionados para participação neste programa por apresentarem potencial de desenvolvimento de projetos diferenciados e inovadores nas suas respectivas secretarias.

A amostra foi definida por conveniência de acesso diante dos retornos dos questionários emitidos, totalizando 25 empreendedores corporativos na pesquisa.

O instrumento de coleta de dados se caracterizou por um questionário estruturado com perguntas fechadas, desenvolvido por Lenzi (2008), que permitiu a identificação das competências de empreendedores corporativos também no ambiente público. A aplicação se deu por colegas de trabalho, eliminando o fator de supervalorização das ações 
desenvolvidas e caracterizadas como empreendedoras no meio público.

Este instrumento foi proposto a partir de um constructo de abordagens teóricas voltadas aos profissionais de empresas estudados por Pinchot (1989), Fleury $(2000,2002)$ e Dutra (2004), dentre outros, integrados aos estudos de empreendedores independentes e corporativos levantados por McClelland (1972), Cooley (1990), Spencer Jr. \& Spencer (1993), na busca de uma conformidade e relação entre estes estudos para uma definição de características e competências similares.

A lógica deste instrumento de pesquisa seguiu o modelo de competências de Cooley (1990) e Spencer Jr. \& Spencer (1993) por configurar a abordagem mais adequada sobre empreendedores. Portanto, as competências analisadas foram as seguintes: busca de oportunidades e iniciativa, disposição para correr riscos calculados, exigência de qualidade e eficiência, persistência, comprometimento, busca de informações, estabelecimento de metas, planejamento e monitoramento sistemáticos, persuasão e rede de contatos e independência e autoconfiança. Este instrumento teve como base as ações práticas realizadas pelos respondentes, caracterizadas em escalas previamente definidas, permitindo uma avaliação quantitativa da percepção dos respondentes diante dos requisitos subjetivos propostos no instrumento.

A limitação da pesquisa é apontada pelo fato de a aplicação desta pesquisa se dar apenas em uma prefeitura municipal com 25 empreendedores corporativos. Porém, o método pode ser amplamente replicado em outros ambientes, permitindo a confirmação - ou não - dos resultados apresentados.

\section{RESULTADOS}

A partir dos objetivos propostos e da fundamentação teórica deste artigo, é possível apresentar alguns aspectos fundamentais neste capítulo, com base nos resultados da pesquisa realizada.

Atribuiu-se como parâmetro de competências o estudo Cooley (1990, 1991), integrado aos estudos de Spencer Jr. \& Spencer (1993), McClelland (1972) e Pinchot (1989), que considerou dez competências comuns entre os empreendedores, porém sem a comparação de metamodelo proposto por McClelland (1972) e Spencer Jr. \& Spencer (1993). Dessa forma, o instrumento de pesquisa desenvolvido por Lenzi (2008), a partir da abordagem de competências de Fleury $(2000,2002)$ e Dutra (2004), permite a identificação da presença das seguintes competências nos empreendedores corporativos: $\mathrm{BOI}$ - busca de oportunidades e iniciativa; CRC - corrida de riscos calculados; EQE - exigência de qualidade e eficiência; PER - persistência; COM - comprometimento; BDI - busca de informações; EDM - estabelecimento de metas; PMS - planejamento e monitoramento sistemáticos; PRC - persuasão e rede de contatos; IAC - independência e autoconfiança.

As observações e constatações realizadas nesta pesquisa levam às análises de identificação dos empreendedores corporativos na administração pública.

\subsection{Identificação dos empreendedores corporativos}

O levantamento em relação à presença dos empreendedores corporativos ocorreu naturalmente por já haver um programa de formação e capacitação interno na Prefeitura de Blumenau, amparado por este conceito de empreendedorismo voltado à inovação e ao desenvolvimento de novos projetos.

A área de recursos humanos da prefeitura, por intermédio da gerência de capacitação, mantém um programa desde 2009 intitulado de PIM - Programa de Inovação e Melhoria. O referido programa consiste em estimular a formação de equipes de trabalho, envolvendo servidores efetivos e comissionados, com o intuito de desenvolver ideias e projetos que possam resultar em melhorias do ambiente de trabalho, geração de novos serviços internos, novos serviços ao cidadão e inovação de processos e ações voltadas à população.

Atualmente, o programa mantém 11 equipes ativas, e a intenção do poder público é ampliar o contingente a cada ano, considerando que o interesse surge com os resultados que são apresentados pelas equipes em atividade.

Cada equipe participa de um curso de capacitação e orientação para conceitos de qualidade e empreendedorismo, possibilitando que as reuniões progra- 
madas posteriormente tenham uma uniformidade de conceitos.

Com estas ações desenvolvidas pelo PIM, a Prefeitura de Blumenau considera ter, na sua estrutura, o início de uma ação empreendedora que poderá perdurar ao longo dos anos, sem que haja interferência política na mudança de mandatos. Isto porque a formação da equipe gestora já está sendo pensada com o envolvimento de servidores de carreira, que poderão manter estas atividades constantes no município.

As ações são, ainda, estritamente de melhorias do ambiente de trabalho, da comunicação interna e de implantação de processos internos. Porém, há de se ressaltar que estas ações implementadas estimulam os participantes na busca de novos horizontes de criação, o que poderá resultar em ações de inovação com reflexos sobre a população.

Uma característica importante de se observar nesta ação de empreendedorismo corporativo é a mudança de cultura interna dos servidores, pois até então não havia espaço para novas ideias e novos projetos, mesmo que simples, senão aqueles determinados pelo escopo gerencial ou político. Este fator demandou mais empenho da equipe gestora em conseguir com que os servidores acreditassem que se trata de um programa de continuidade, e não apenas de modismo passageiro, mas tem se consolidado com projetos de impacto interno.

Outra característica do programa é que ele não tem uma motivação política, e sim um embasamento técnico que é conduzido pelas bases teóricas do empreendedorismo corporativo, por meio das quais a organização oferece espaço para geração de novas ideias e inovação, proporciona capacitação constante e permanente, avalia os reflexos da ação, reconhecendo os projetos e os respectivos resultados, e estimula a participação de todos os servidores com uma comunicação permanente no quadro de pessoal.

No Quadro 1, é possível observar a interação das secretarias nos projetos em andamento e o número de servidores participantes ativamente.

O envolvimento direto de 73 servidores nos projetos de melhoria parece pequeno diante do conjunto de quase sete mil servidores estáveis ou temporários que a prefeitura possui em seus quadros. Porém, é possível observar a crença de que a cultura empreendedora se estabelece aos poucos no conjunto de resultados aferidos ao longo deste período.

Em entrevista com a equipe gestora do projeto, percebe-se que há um crescente envolvimento dos servidores no PIM, considerando-se ser este o primeiro ano de implantação. A expectativa é que, ao longo dos anos, haja um acelerado aumento de participantes e equipes, levando ao contexto de melhoria contínua em muitos ambientes de trabalho e estabelecendo um ambiente criativo que poderá e deverá se concretizar na geração de novos serviços internos, novos serviços ao cidadão e inovação de processos e ações voltadas à população.

\subsection{Competências dos empreendedores corporativos}

$\mathrm{Na}$ análise dos resultados dos empreendedores corporativos, observou-se a presença das competências empreendedoras, conforme evidencia o Gráfico 1.

Neste gráfico, é possível constatar que as quatro competências empreendedoras mais presentes nos pesquisados são comprometimento (24 empreendedores corporativos), busca de informações (22 empreendedores corporativos), persistência (22 empreendedores corporativos) e planejamento e monitoramento sistemático (20 empreendedores corporativos).

Já em relação à pontuação das competências empreendedoras pesquisadas, constatou-se que 12,9 foi a média mensurada. No Gráfico 2, é possível observar a pontuação de cada uma das dez competências.

No caso dos empreendedores corporativos pesquisados, constata-se que nove competências obtiveram pontuação igual ou maior que a linha de corte de 12 pontos para apontar a presença das mesmas nos empreendedores, tendo o predomínio das competências de comprometimento (14,4 pontos), da persistência (13,7 pontos) e da busca de informações (13,7 pontos) como as mais pontuadas.

A única competência que não obteve a pontuação da linha de corte (12 pontos) foi a de independência e autoconfiança. Porém, mesmo esta estando abaixo 


\section{Quadro 1: Ações de empreendedorismo corporativo nas diversas secretarias, autarquias e fundações}

\begin{tabular}{|c|c|c|c|}
\hline Secretaria & $\begin{array}{l}\text { Número de } \\
\text { servidores } \\
\text { participantes }\end{array}$ & Projetos implantados & $\begin{array}{c}\text { Projetos em } \\
\text { desenvolvimento }\end{array}$ \\
\hline $\begin{array}{l}\text { Secretaria de } \\
\text { Assistência Social e } \\
\text { Conselho Municipal } \\
\text { de Entorpecentes } \\
\text { (Comen) }\end{array}$ & 04 & 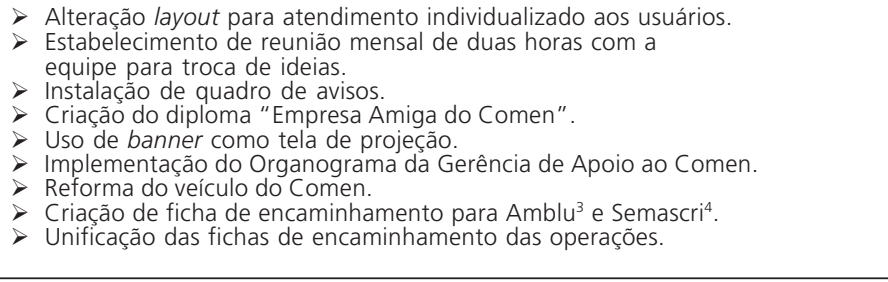 & $\begin{aligned} \text { Disponibilização de } \\
\text { psicólogo para assessoria } \\
\text { aos funcionários do Comen. } \\
\text { Definição de procedimentos } \\
\text { para internação através do } \\
\text { convênio. } \\
\text { Aquisição de máquina } \\
\text { fotográfica digital. } \\
\text { Realização de reuniões } \\
\text { bimestrais com a diretoria } \\
\text { de Proteção Especial. }\end{aligned}$ \\
\hline $\begin{array}{l}\text { Secretaria de Educação } \\
\text { e Secretaria de } \\
\text { Orçamento e Gestão }\end{array}$ & 03 & $\begin{array}{l}>\text { Digitalização dos documentos dos alunos pelas secretarias de escolas. } \\
>\text { Arquivamento em local virtual na Prefeitura. } \\
>\text { Levantamento da infraestrutura (Internet/scaners) disponível. } \\
>\text { Criação do software. } \\
>\text { Treinamento de servidores. } \\
>\text { Implantação de filtro (GNexus). }\end{array}$ & $\begin{array}{l}\text { Realização de melhorias } \\
\text { no sistema. }\end{array}$ \\
\hline $\begin{array}{l}\text { Intendência Distrital } \\
\text { do Bairro Garcia }\end{array}$ & 06 & $\begin{array}{l}>\text { Reciclagem do lixo. } \\
\text { Promoção dos } 55^{5} \text { nas dependências da Intendência. }\end{array}$ & $\begin{array}{l}>\text { Solicitação de lombada } \\
\text { eletrônica. } \\
>\text { Criação de sala para descanso. }\end{array}$ \\
\hline $\begin{array}{l}\text { Procuradoria Geral } \\
\text { do Município e } \\
\text { Controladoria Interna }\end{array}$ & 04 & $\begin{array}{l}>\text { Práticas administrativas (descrição de função, Regimento Interno). } \\
>\text { Mudança de estrutura. }\end{array}$ & \\
\hline $\begin{array}{l}\text { Secretaria de } \\
\text { Orçamento e Gestão } \\
\text { e Praça do Cidadão }\end{array}$ & 08 & $\begin{array}{l}>\text { Reorganização do espaço físico. } \\
\text { Solicitação e conserto das tomadas. } \\
\text { C Confecção de projeto de armário e levantamento do orçamento. } \\
\text { Levantamento de orçamento para conserto do bebedouro. } \\
>\text { Encaminhamento dos orçamentos para a Secretaria. }\end{array}$ & $\begin{array}{l}\text { Verificação da possibilidade } \\
\text { de instalação de pia na } \\
\text { cozinha. }\end{array}$ \\
\hline Parque Vila Germânica & 11 & $\begin{array}{l}>\text { Informativo dos eventos realizados no parque. } \\
\text { Fixação de quadro de localização dos colaboradores. } \\
\text { Implantação do quadro de avisos. } \\
\text { Decoração natalina. } \\
\text { A Aquisição de suporte para elevar as telas dos computadores. } \\
\text { > Realização de festa de encerramento.. }\end{array}$ & $\begin{array}{l}\text { Levantamento dos custos } \\
\text { para reforma da casa de } \\
\text { uma servidora (auxílio). }\end{array}$ \\
\hline $\begin{array}{l}\text { Secretaria de } \\
\text { Administração }\end{array}$ & 07 & $\begin{array}{l}\text { Aplicação dos } 5 \mathrm{~S} \text {. } \\
\text { Confecção de um mural de localização e atualização do mural de aniversário. } \\
\text { Padronização dos arquivos do computador. } \\
\text { > Atualização da lista telefônica. } \\
\text { Digitalização das listas de presença dos cursos já oferecidos. } \\
\text { Organização dos arquivos no armário. } \\
>\text { Criação de checklist das capacitações. }\end{array}$ & $\begin{array}{l}\text { Criação de reunião } \\
\text { técnica em } 2011 \text { com } \\
\text { quem acompanha e } \\
\text { ministra capacitações. }\end{array}$ \\
\hline $\begin{array}{l}\text { Fundação Cultural } \\
\text { e Arquivo Histórico }\end{array}$ & 10 & $\begin{array}{l}\text { Implantação da caixa de ideias. } \\
\text { Desenvolvimento de um catálogo iconográfico (acervo de quadros, } \\
\text { porta-retratos, gravuras, ilustrações e documentos). } \\
>\text { Reorganização do espaço físico. } \\
>\text { Elaboração de Regimento Interno. } \\
>\text { Reformulação da ficha de atendimento. }\end{array}$ & \\
\hline $\begin{array}{l}\text { Fundação Cultural e } \\
\text { Secretaria de Comunicação }\end{array}$ & 06 & & $\begin{array}{l}\text { Melhoria do indicador do } \\
\text { público presente nos eventos } \\
\text { realizados na instituição. } \\
\text { Credibilidade nos prazos } \\
\text { antecipados da divulgação de } \\
\text { eventos; } \\
\text { Restabelecimento da confiança } \\
\text { da comunidade na } \\
\text { disseminação dos eventos } \\
\text { culturais. }\end{array}$ \\
\hline Fundação Cultural & 08 & $\begin{aligned} & \text { Criação e divulgação do material gráfico, produzido para divulgação dos } \\
& \text { eventos da cidade. } \\
& \text { Criação de formulário de atendimento com detalhamento do chamado. } \\
&> \text { Implantação do quadro de avisos. } \\
& \text { Reunião semanal. } \\
&>\text { Funcionamento de caixa de ideias. }\end{aligned}$ & $\begin{array}{l}>\text { Criação de manual de } \\
\text { procedimento. } \\
>\text { Organização dos arquivos no } \\
\text { armário. } \\
>\text { Efetivação de arquivo digital }\end{array}$ \\
\hline Secretaria de Administração & 06 & $\begin{array}{l}>\text { Implantação do quadro de informações. } \\
\text { Reaproveitamento de mobiliário. } \\
>\text { Colocação de caixas na sala } 28 \text { para recolhimento de papel para reciclagem. }\end{array}$ & $\begin{array}{l}\text { Concepção de novo layout } \\
\text { para a sala. }\end{array}$ \\
\hline
\end{tabular}

Fonte: Secretaria de Administração da Prefeitura de Blumenau.

${ }^{3}$ Abrigo Municipal de Blumenau.

${ }^{4}$ Secretaria da Assistência Social, da Criança e do Adolescente.

${ }^{5}$ Trata-se de um expediente de origem japonesa, os "cinco sensos" (o nome provém de cinco palavras japonesas iniciadas pela letra "s": Seiri, Seiton, Seisou, Seiketsu e Shitsuke, respectivamente correspondendo a utilização, organização, zelo, higiene e disciplina). 
Gráfico 1: Distribuição do número de empreendedores independentes por competência

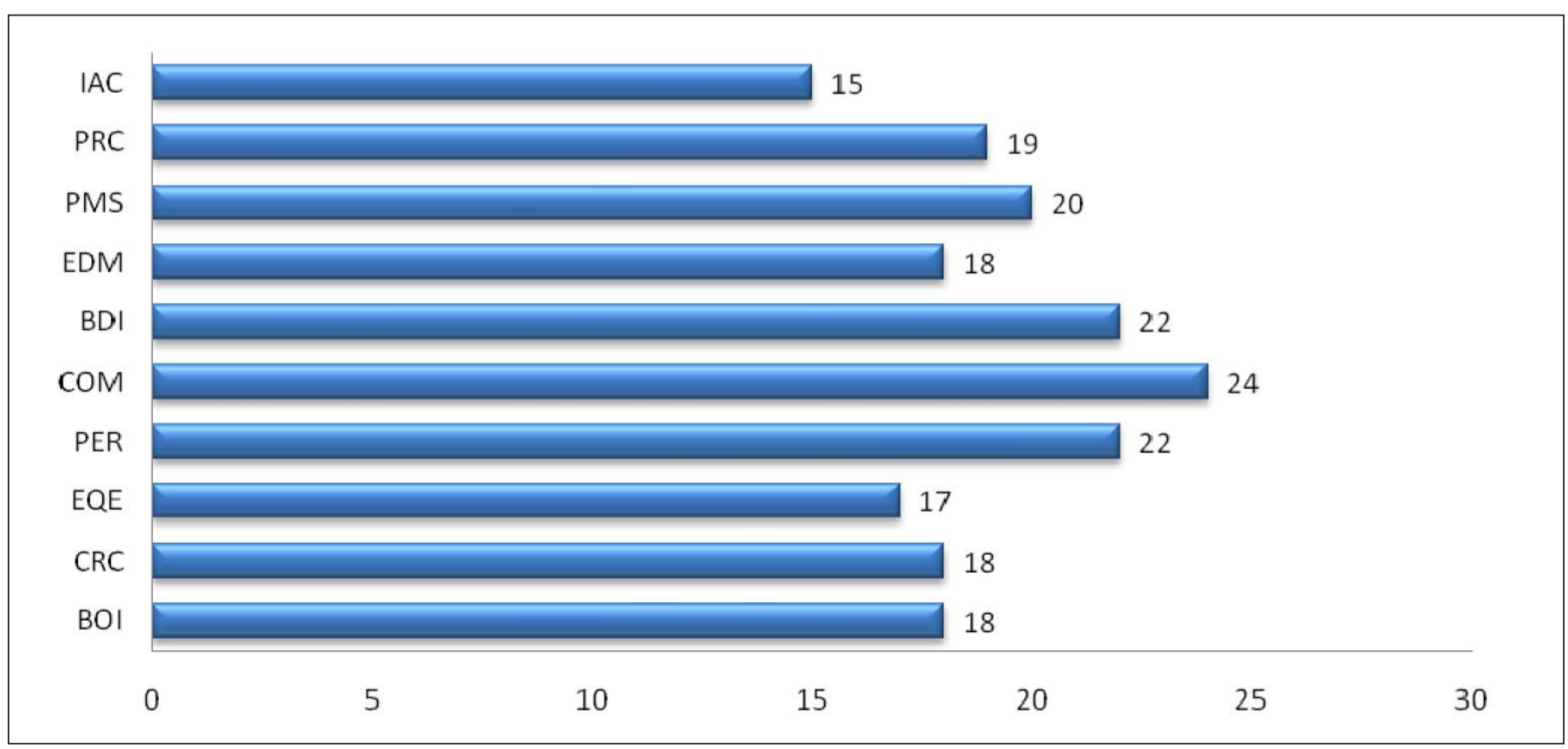

Fonte: dados da pesquisa

Gráfico 2: Média de pontuação dos empreendedores independentes por competência

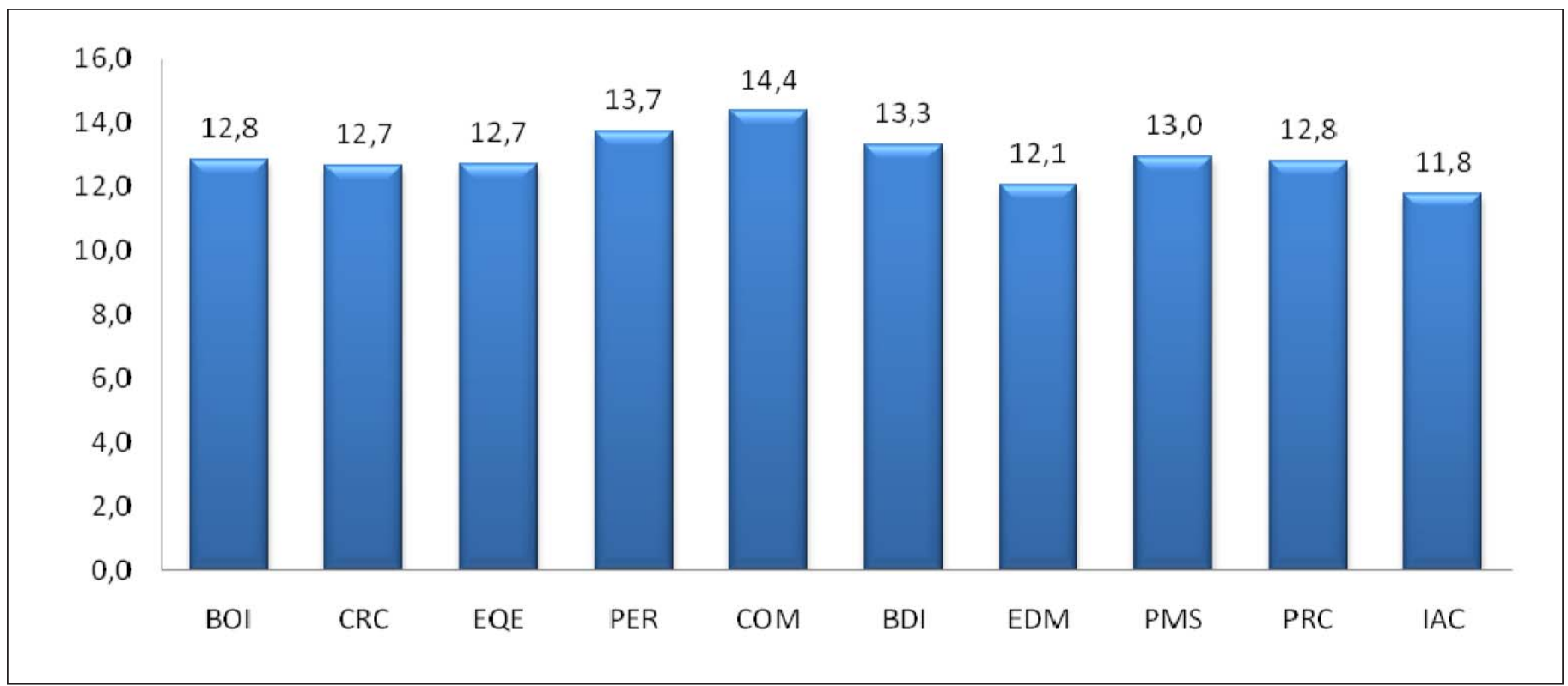

Fonte: dados da pesquisa.

da pontuação mínima, ficou bem próxima, com 11,8 pontos.

Observando-se a distribuição dos 25 empreendedores pelo número de competências identificadas, percebese que o predomínio maior é de dez competências presentes com 11 empreendedores corporativos se caracterizando por possuírem estas competências (Tabela 1). É possível constatar, também, que não há empreendedores apresentando menos de três competências empreendedoras. 
Tabela 1: Distribuição do número de colaboradores por competências empreendedoras, segundo pontuação individual

\begin{tabular}{cc}
\hline $\begin{array}{c}\text { Número de } \\
\text { competências }\end{array}$ & $\begin{array}{c}\text { Número de } \\
\text { empreendedores }\end{array}$ \\
\hline 0 & 0 \\
\hline 1 & 0 \\
\hline 2 & 0 \\
\hline 3 & 1 \\
\hline 4 & 2 \\
\hline 5 & 4 \\
\hline 6 & 2 \\
\hline 7 & 1 \\
\hline 8 & 3 \\
\hline 9 & 1 \\
\hline 10 & 11 \\
\hline Total & 25 \\
\hline
\end{tabular}

Fonte: dados da pesquisa.

A partir dos resultados apresentados, as considerações finais possibilitam uma análise destes dados com base na prática observada ao longo da pesquisa e das competências empreendedoras identificadas nos servidores reconhecidos como empreendedores corporativos.

\section{CONSIDERAÇÕES FINAIS}

A realização desta pesquisa, que teve como objetivo identificar as competências dos empreendedores corporativos ligados à administração pública, permitiu uma análise do ponto de vista organizacional quando não há interferência política em ações que geram inovação e novos projetos para comunidade.

Neste estudo, o ambiente pesquisado foi direcionado à administração municipal, especificamente analisando-se o caso de uma prefeitura, da cidade de Blumenau. Apesar de os resultados não poderem ser generalizados quanto à identificação do que se pratica de empreendedorismo corporativo em organizações públicas, é possível afirmar, com base na investigação efetuada, que é perfeitamente adequada a configuração do tema na área pública.
Ficou evidenciado, por meio de levantamentos, entrevistas e observações realizadas, que a implantação de programas que estimulem a inovação na área pública deve estar desvinculada dos aspectos políticos, que também compõem o ambiente organizacional deste meio. Não é uma afirmação do que é mais adequado ou menos adequado na administração pública, mas sim uma constatação de que a baixa influência política em ações de cunho técnico tende a gerar resultados mais concretos para o meio.

O envolvimento de servidores de carreira e a mudança cultural estimulada com programas de capacitação e formação empreendedora ajudaram muito na configuração de um programa de estímulo ao desenvolvimento de projetos empreendedores. Analisando-se as bases teóricas do tema, pode-se afirmar que o espaço oferecido pela organização, seja pública, seja privada, é essencial e fundamental para que as ações se traduzam em resultados efetivos.

O caso analisado permite considerar que a mudança cultural para um perfil organizacional mais aberto e a credibilidade deste tipo de programa, em um ambiente culturalmente fechado, ocorre a partir do reconhecimento público dos resultados e da implementação dos projetos sugeridos e desenvolvidos pelos servidores envolvidos.

Diante deste quadro de formação de um ambiente empreendedor, é possível identificar, também, quais competências empreendedoras estão mais latentes entre os pesquisados, que, em muitos momentos, encontram-se envolvidos no citado Programa de Inovação e Melhoria (PIM) ou em outras atividades que demandam a geração de projetos inovadores.

As cinco competências empreendedoras mais frequentes detectadas entre os indivíduos pesquisados foram as seguintes: comprometimento (COM), busca de informações (BDI), persistência (PER), planejamento e monitoramento sistemático (PMS) e persuasão e rede de contatos (PRC). Analisando-se este conjunto de competências, constata-se que, no caso em estudo, estas se assemelham a outras pesquisas de empreendedorismo corporativo, em especial ao trabalho realizado por Lenzi (2008). Estas competências estão diretamente relacionadas a um perfil corporativo, no qual, apesar de empreendedores, os profissionais têm 
algumas limitações de ação que os diferenciam de empreendedores individuais que possuem suas próprias empresas.

Considerando-se ser um ambiente público, onde a estabilidade é um fator muito forte na diferenciação com a iniciativa privada, destaca-se, neste conjunto de competências empreendedoras que mais se evidenciaram na pesquisa, o comprometimento com a maior pontuação. Seria natural entender que o comprometimento não fizesse parte deste conjunto, porém foi o mais forte dentre todas. De forma objetiva, pode-se lembrar que os pesquisados já foram selecionados levando-se em conta seu perfil diferenciado, o que leva a crer que, para estes profissionais, a estabilidade não é um valor fundamental do serviço público ou não se torna motivo de acomodação.

Em relação às competências empreendedoras menos frequentes entre os pesquisados, podem ser destacadas independência e autoconfiança (IAC), exigência de qualidade e eficiência (EQE), estabelecimento de metas (EDM), corrida riscos calculados (CRC) e busca de oportunidades e iniciativa (BOI).
Todas essas competências parecem naturalmente aderentes ao contexto corporativo, em especial ao ambiente público, visto que há muitas limitações nas ações desenvolvidas pelos profissionais empreendedores.

Mesmo tendo na base da pesquisa profissionais considerados empreendedores, o ambiente e a cultura pública podem interferir em algumas ações que se refletem nas competências de menor destaque entre os entrevistados.

Ressalta-se que este artigo revela os levantamentos realizados em um único caso, mas a sugestão de novas pesquisas com outros casos nesta configuração pode ser ressaltada para que haja um conjunto de dados capazes de desenvolver uma análise cruzada das diversas situações e dos vários empreendedores corporativos envolvidos.

Outra sugestão de pesquisa a realizar fica por conta do levantamento dos valores de cada indivíduo em seu ambiente de trabalho, associado ao conjunto de competências empreendedoras mensuradas pelos resultados produzidos na organização, seja ela pública, seja privada.

\section{REFERÊNCIAS}

Araúso, Eduardo B. de. Entrepreneurship e intrapreneurship: uma trajetória literária de 1979 a 1988. Revista de Administração de Empresas, v. 28, n. 4, p. 67-76, São Paulo, outubro/dezembro, 1988.

BAUMAN, Zygmunt. Vida líquida. Rio de Janeiro: Jorge Zahar, 2007.

ChaUí, Marilena. O retorno do teológico-político. In: CARdoso, Sérgio. Retorno ao republicanismo. Belo Horizonte, UFMG, 2004. p. 93-133.

COOLEY, Larry. Entrepreneurship training and the strengthening of entrepreneurial performance. Final Report. Contract n. DAN-5314-C-00-3074-00. Washington: Usaid, 1990.

Seminário para Fundadores de Empresa. Manual del Capacitador. Washington: MSI, 1991.

Cooper, Donald R. \& SCHindLer, Pamela S. Business reserch methods. Irwin: McGraw-Hill, 1995.

Cox, Allan J. O perfil realizador: 100 perguntas e respostas para aguçar seus instintos de executivo empreendedor. Ediouro, Rio de Janeiro, 1994.
Degen, Ronald. O empreendedor: fundamentos da iniciativa empreendedora. São Paulo: McGraw-Hill, 1989.

Draibe, Sônia Miriam. Estado de bem-estar, desenvolvimento econômico e cidadania: algumas lições da literatura contemporânea. In: Hochman, Gilberto; Arretche, Marta \& Marques, Eduardo (orgs.). Políticas públicas no Brasil. Rio de Janeiro: Fiocruz, 2007. p. 27-64.

DRUCKER, Peter F. Inovação e espírito empreendedor (entrepreneurship): prática e princípios. São Paulo: Pioneira, 1986.

Dutra, Joel Souza. Gestão de pessoas com base em competências. In: Dutra, Joel Souza (org.). Gestão por competências. Um modelo avançado para o gerenciamento de pessoas. São Paulo: Gente, 2001. p. 25-44.

Competências: conceitos e instrumentos para a gestão de pessoas na empresa moderna. São Paulo: Atlas, 2004.

FARReL, Larry C. Entrepreneuriship: fundamentos das organizações empreendedoras. São Paulo: Atlas, 1993. 


\section{REFERÊNCIAS}

Fleury, Afonso C. C. \& Fleury, Maria Tereza L. Estratégias empresariais e formação de competências. São Paulo: Atlas, 2000.

FleUry, Maria Tereza L. As pessoas na organização. São Paulo: Gente, 2002.

FREY, Klaus. Governança urbana e participação política. In: XXVIII Encontro da Associação Nacional de Pós-Graduação e Pesquisa em Administração - EnAnpad. Anais... Curitiba: Anpad, 2004.

GIL, Antonio Carlos. Métodos e técnicas de pesquisa social. São Paulo: Atlas, 1999.

Guglano, Alfredo Alejandro. Democracia, participação e deliberação. Contribuições ao debate sobre possíveis transformações na esfera democrática. Civitas - Revista de Ciências Sociais. Democracia e novas formas de participação política. PUCRS, v. 4, n. 2, p. 257-284, Porto Alegre, julho/dezembro, 2004.

LAWLER III, Edward E. Competencies: a poor foundation for the new pay. Compensation \& Benefits Review, v. 28, n. 6, p. 20-26, November/December, 1996.

Le Boterf, Guy. De la competence: essai sur un attracteur étrange. Paris: Éditions d'Organisation, 1994.

LEITE, Roberto C. De executivo a empresário: como realizar o seu ideal de segurança e independência. Rio de Janeiro: Campus, 1998.

LeNZI, Fernando César. Os empreendedores corporativos nas empresas de grande porte: um estudo da associação entre tipos psicológicos e competências empreendedoras. 2008. Tese (Doutorado em Administração) - Faculdade de Economia, Administração e Contabilidade da Universidade de São Paulo. São Paulo: FEA/USP.

LenzI, Fernando César; SAntos, Sílvio Aparecido dos; CASAdo, Tânia \& RodRigues, Leonel César. Talentos inovadores na empresa. Curitiba: Ibpex, 2011.

LIPOVETSKY, Gilles. A sociedade pós-moralista. O crepúsculo do dever e a ética indolor dos novos tempos democráticos. Barueri: Manole, 2005.

Mascarenhas, André Ofenhejm; Vasconcelos, Flávio Carvalho \& VAsconcelos, Isabella F. Gouveia. Gestão do paradoxo: discurso versus prática - aprendizagem e informatização da administração de RH. In: VAsConcelos, Flávio de Carvalho \& VAsconcelos, Isabella F. Gouveia. Paradoxos organizacionais: uma visão transformacional. São Paulo: Pioneira Thomson, 2004. p. 75-106.
McClelland, David C. A sociedade competitiva: realização e progresso social. Rio de Janeiro: Expressão e Cultura, 1972.

Mattar, Fauze N. Pesquisa de marketing. Edição compacta. São Paulo: Atlas, 1996.

Miner, John B. Os quatro caminhos para o sucesso empresarial: como acertar o alvo no mundo dos negócios. São Paulo: Futura, 1998.

Nogueira, Marco Aurélio. Um Estado para a sociedade civil. Temas éticos e políticos da gestão democrática. São Paulo: Cortez, 2004.

Administradores e políticos. O Estado de S. Paulo, São Paulo, Cad. A2, 23 de agosto de 2008.

Orsi, Ademar \& Bose, Mônica. Gestão por competência: modelo e abrangência. Revista de Psicologia, Universidade Federal do Ceará, v. 21, n. 1-2, p. 64-79, Fortaleza, janeiro/dezembro, 2003.

Paes de Paula, Ana Paula. Por uma nova gestão pública. Rio de Janeiro: FGV, 2005.

Pinchot, Gifford \& PelLman, Ron. Intraempreendedorismo na prática: um guia de inovação nos negócios. Rio de Janeiro: Elsevier, 2004.

PINCHOT III, Gifford. Intrapreneuring: porque você não precisa deixar a empresa para tornar-se empreendedor. São Paulo: Harbra, 1989.

SCENNETT, Richard. A cultura do novo capitalismo. São Paulo: Record, 2006

SeIFFERT, Peter Q. Empreendendo novos negócios em corporações. São Paulo: Atlas, 2005.

Seiffert, Peter Q \& Santos, Sílvio Aparecido dos. Desenvolvimento de novos negócios em corporações: um modelo aplicado. Revista de Práticas Administrativas, v. 1, n. 1, p. 20-34, Maringá, julho/agosto, 2004.

Spencer JR., Lyle M. \& Spencer, Signe M. Competence at work: models for superior performance. New York: John Wiley and Sons, 1993.

VALLE, Rogério. O conhecimento em ação: novas competências para o trabalho no contexto da reestruturação produtiva. Rio de Janeiro: Relume Dumará, 2003.

VIEIRA, Liszt. Os argonautas da cidadania. A sociedade civil na globalização. Rio de Janeiro: Record, 2001.

ZAHRA, Shaker A. Predictors and financial outcomes of corporate entrepreneurship: an exploratory study. Journal of Business Venturing, v. 6, n. 4, p. 259-285, July, 1991. 